\title{
FORMAÇÃO CONTINUADA EM SERVIÇO EM CONTEXTOS DESCENTRALIZADOS
}

\author{
Vicente Rodriguez* \\ Domingos Pereira da Silva**
}

\begin{abstract}
RESUMO: Em razão da importância da formação continuada de professores para as políticas educacionais e das diferenças e desigualdades existentes entre os municípios, discute-se aqui o viés centralista que utiliza o controle avaliativo para implementar o regime de colaboração nas políticas educacionais. A partir da reforma gerencial do Estado da década de 1990, busca-se explicitar, pela análise das orientaçóes gerais e dos aspectos específicos desta temática, a forma de desenvolvimento da política de formação continuada de professores. No contexto da realidade concreta, observa-se um processo de reconfiguração entre descentralização e concentração, provocada pelo redimensionamento das relaçóes entre Estado e sociedade em um movimento de desconcentração.
\end{abstract}

Palavras-chave: Estado. Centralização. Desconcentração. Formação continuada de professores.

\footnotetext{
* Universidade Estadual de Campinas, Faculdade de Educação (Unicamp/FE), Campinas, SP., Brasil. E-mail de contato: virodri@unicamp.br.

** Prefeitura do Município de Miracema, Secretaria Municipal de Educação, Miracema, TO., Brasil. E-mail de contato: domingosps@uft.edu.br.
} 


\title{
Continuing in-service teacher education in decentralized contexts
}

\begin{abstract}
Taking into consideration the importance of continuing teacher education for the educational policies and the differences and inequalities between municipalities, the aim of this text is to discuss the centrist bias using the evaluative control to implement the regime of collaboration in educational policies. Based on the managerial state reform of the 1990s, and by analysing the general guidelines and the specific aspects of this theme, we search to clarify the way the continuing teacher education policy has been developed. In the context of concrete reality, there has been a reconfiguration process between decentralization and concentration caused by the resizing of relations between the State and society in a de-concentration movement.
\end{abstract}

Keywords: State. Centralization. De-concentration. Continuing teacher education.

\section{INTRODUÇÃO}

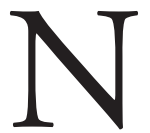

este artigo discutiremos, de forma geral, de duas questôes: a primeira versa sobre o Estado capitalista, a partir da perspectiva marxista; e em um segundo momento, buscaremos problematizar a Política Nacional de Formação de Professores no Brasil, no início do século XXI.

Importa destacar que muito se tem produzido a respeito das políticas educacionais e que na complexa produção de diagnósticos dos últimos 30 anos, em sua quase totalidade, a formaçáo do professor se constitui em um elemento fundamental. Do mesmo modo, na multivariada e antagônica forma de enfrentar as dificuldades do aparato educacional, a valorização e a formação do professor encontram um lugar de destaque.

Com esse intuito, tomamos como referência de análise a premissa de que as políticas educacionais expressam o modelo de Estado, 
que se assenta no redimensionamento do modo de produçáo hegemônico, no contexto do desdobramento da política de descentralização/ centralização, que, por sua vez, está intrinsecamente relacionada ao processo de reforma do Estado da última década do século XX.

Em linhas gerais, o Estado como condensação das relaçóes de classe, conforme análise de Poulantzas (2000), em um processo de acumulaçáo do capital, fornece elementos fundamentais para a compreensão das políticas públicas. No caso analisado a seguir, a política nacional de formação de professores organiza-se para responder às novas condições colocadas pela centralização, pela internacionalização e pela financeirização do capital educacional no Brasil contemporâneo.

\section{BREVE ANÁLISE DO ESTADO CAPITALISTA}

Ao compartilhamos do entendimento de que o Estado expressa conceitualmente a condensação das relaçóes de classe que se corporificam no que Gramsci (2010) denominou de relaçôes hegemônicas, entendemos que o Estado não se reduz ao governo ou ao povo; logo, o estabelecimento da hegemonia náo se processa somente pela força ou pelo convencimento, mas, sim, pela correlação de forças que organicamente abarca a dialética entre ambas. Com efeito, para Gramsci (2010, p. 20-21):

[...] podem se fixar dois grandes 'planos' superestruturais: o que pode ser chamado de 'sociedade civil', (isto é, o conjunto de organismos designados vulgarmente como 'privados') e o da 'sociedade política ou Estado', planos que correspondem, respectivamente, à função de 'hegemonia', que o grupo dominante exerce em toda a sociedade e àquela de 'domínio direto' ou de comando, que se expressa no Estado e no governo 'jurídico’.

Assim, em função do caráter ontológico que perpassa a concepção de Estado ampliado em Gramsci, chamamos a atenção para dois 
equívocos centrais da análise a respeito da sociedade civil e sociedade política. O primeiro as trata como categorias totalmente distintas, como se não expressassem correlaçóes orgânicas. $\mathrm{O}$ segundo entende sociedade política e sociedade civil de forma indiferenciada, ignora a relação dialética de unidade-distinção.

Em contraposição aos equívocos levantados, entendemos que sociedade civil e sociedade política não são instâncias separadas, mas, sim, um constructo que abarca de forma dialética relaçóes de coerção e consenso.

Destarte, a hegemonia da sociabilidade burguesa vem se realizando mediante a reconfiguração de estratégias que buscam dar respostas às crises do capital, sem que, necessariamente, as relaçôes de classes sejam colocadas em discussão. De um modo geral, estas têm-se assentado nos pressupostos de três correntes: a keynesiana, a neoliberal e a de "terceira via”.

Para fins desta análise enfocaremos a "terceira via" considerada como a reconfiguração do neoliberalismo. Destacamos, portanto, as ideias do sociólogo Anthony Giddens (2005) tido como o principal sistematizador desse projeto político, econômico e cultural.

Em conformidade com Anderson (2000, p. 13), podemos dizer que "[...] a 'terceira via' é, hoje, a concha ideológica mais adequada ao neoliberalismo [...]". É nesse sentido que Silva e Rodriguez (2013, p. 128), ao realizarem uma análise sobre a incidência da "terceira via" na política educacional brasileira, asseveram que esta traz em sua estrutura a autopreservação do projeto neoliberal, como uma "[...] estratégia capciosa de reconfiguração das orientaçóes que não foram implementadas em sua plenitude pelo neoliberalismo [...]".

Com efeito, o projeto político e econômico da "terceira via" promove uma culturalização sutil do ideário neoliberal e é caracterizado por Giddens (2005, p. 36) como:

[...] uma estrutura de pensamento e de prática política que visa a adaptar a social-democracia a um mundo que se transformou fundamentalmente ao longo das duas ou três últimas décadas. É uma terceira via no 
sentido de que é uma tentativa de transcender tanto a social-democracia do velho estilo quanto o neoliberalismo.

Assim, em virtude da falta de possibilidades políticas da "direita" e da "esquerda", seria inevitável que todas as forças políticas optassem pelo "centro radical", cuja pauta consiste na defesa da "humanização do capitalismo", na garantia da igualdade de oportunidade para todos e na democratização da democracia. (GIDDENS, 1996, 2005)

É mister destacar a centralidade da estratégia de repolitização que atravessa o programa teórico-político da "terceira via", pois as categorias "sociedade civil ativa" e "democratização da democracia", que lhe são constitutivas, apenas reiteram a defesa de que "[...] uma sociedade que não estimula a cultura empresarial não pode gerar a energia econômica que provém das ideias mais criativas [...]”. (GIDDENS, 2001, p. 80)

Com efeito, apesar de a "terceira via" esboçar crítica às teses neoliberais, tidas como ortodoxas, ela reafirma o projeto neoliberal, ao pressupor que

[...] a maioria dos governos ainda tem um bocado a aprender com a melhor prática empresarial - por exemplo, controle de metas, auditorias eficazes, estruturas de decisão flexíveis e maior participação dos funcionários - o último destes sendo um fator de democratizaçấo. (GIDDENS, 2005, p. 84)

Importa acrescentar que, no programa do "neoliberalismo reconfigurado", o modelo de participação se assenta na participação/ execução da "sociedade civil ativa".

Também é preciso apontar que, no Brasil, a introdução da "terceira via" ocorreu com a reforma do Estado, implantada pelo Ministério da Administração e Reforma do Estado (Mare) (MARTINS; GROPPO, 2010), que teve à frente Luiz Carlos Bresser Pereira, de 1995 a 1998. É desse período o Plano Diretor da Reforma do Aparelho de Estado (PDRAE), lançado em 1995, que estabeleceu a orientação vigente das 
políticas em curso e teve como objetivo central a instituição do modelo de "administração gerencial".

No PDRAE são definidos quatro setores do Estado, a saber: o núcleo estratégico, formado pelo Legislativo, pelo Judiciário, pela Cúpula dos Ministérios e pelo Ministério Público; as atividades exclusivas, como regulamentação, fiscalização, segurança pública e seguridade social básica; os serviços não exclusivos, compostos por universidades, hospitais, centros de pesquisa e museus; e a produção para o mercado, representado pelas empresas estatais.

Queremos ressaltar, especificamente, que, na proposta de reforma do Estado, a não inclusão de universidades, escolas, hospitais, centros de pesquisa e museus como atividades exclusivas do Estado, deixando-os relegados à lógica economicista, tem por intento a conversão destes em organizaçóes sociais ${ }^{1}$, ou de outra forma, em organizações públicas não estatais. (BRASIL, 1995)

Destarte, o processo de reforma gerencial do Estado da década de 1990, que se fundamentou na orientação da perspectiva da "terceira via”, estabeleceu que o que não pudesse ser privatizado deveria necessariamente ser publicizado, ou seja, transferido para o "terceiro setor", que se coloca como "parceiro" do Estado - primeiro setor - e do mercado, tido como segundo setor.

Segundo Montaño (2007, p. 22), o termo "terceiro setor" "[...] refere-se na verdade a um fenômeno real inserido na e produto da reestruturação do capital, [ou seja] um novo padrão (nova modalidade, fundamento e responsabilidades) para a funçấo social de respostas às sequelas da 'questão social'[...]".

Apesar de Montaño fazer referência ao processo de descentralização administrativa, é importante acrescentar, em consonância com Viriato (2004. p. 47), outros três planos que compóem a análise sobre a descentralização: o plano político, o plano econômico e a qualidade do ensino. Com efeito,

[...] no plano político, a ênfase reside na participação

e na democracia. No plano econômico, acena por 
recursos. No que se refere à qualidade do ensino, a ênfase recai na questão técnico-pedagógica e, por fim, o plano administrativo exige mais eficiência nos processos educacionais.

Em consonância com o entendimento da autora, coadunamos que “[...] sem participação, sem mecanismos democráticos, sem autonomia para interferir nas questôes administrativas e pedagógicas, não há descentralização [...]”. (VIRIATO, 2004, p. 47) Nesse sentido:

[...] o que está sendo implementado são políticas de desconcentração, uma vez que desconcentrar significa levar a execução para mais perto do lugar em que ocorre o ato educacional, assegurando, assim, os interesses do poder central, assegurando sua eficiência e eficácia. (VIRIATO, 2004, p. 47)

Casassus (1995), na obra intitulada Tarefas da Educação, apresenta uma discussão bastante elucidativa acerca da conceituação de descentralização e, ao sintetizar, afirma que existe uma contraposição entre descentralização e desconcentração.

Nessa linha argumentativa, descentralização diz respeito a “[...] confiar poderes de decisão a órgãos diferentes daqueles do poder central, que não estão submetidos ao dever de obediência hierárquica, e que contam com autoridades democraticamente eleitas [...]" (CASASSUS, 1995, p. 82), ao passo que, na desconcentração, o "objetivo é assegurar a eficácia do poder central”. (CASASSUS, 1995, p. 84) Com isto, queremos frisar

[...] que descentralizar significa redistribuir o poder central, envolvendo necessariamente alteraçôes nos núcleos de poder, que levam a uma maior distribuição do poder decisório até então centralizado em poucas mãos, ao passo que desconcentrar significa delegar determinadas funções à comunidade local, mantendo centralizadas as decisóes sobre os aspectos financeiros, 
administrativos e pedagógicos. (VIRIATO, 2004, p. 47)

A publicização, como uma das faces do processo de repolitização da relação Estado/sociedade, vem sendo estabelecida, especificamente, na forma de desconcentração, que, por sua vez, tem sido corriqueiramente confundida por muitos com descentralização.

Verifica-se, com isso, o deslocamento de responsabilidades, antes atribuídas especificamente ao Estado estrito, para a "sociedade civil ativa”. Isto vem contribuindo expressivamente para o processo de reafirmação, intensificação e diversificação do papel centralizador desempenhado pelo Estado. Assim:

[...] com a separação entre as esferas 'política' e 'econômica', ou seja, o Estado e a sociedade civil, o poder coercitivo público está mais centralizado e concentrado do que nunca, mas isso apenas quer dizer que uma das principais funçōes de coerção 'pública' por parte do Estado é apoiar o poder privado na sociedade civil. (WOOD, 2006, p. 218)

Evidenciamos, portanto, que a problematização do tema centralização/descentralização tem sido feita com base nas perspectivas liberal e democrática. Estas, apesar de possuírem diferentes significados, convergem na defesa pela descentralização.

Neste sentido, importa destacar, conforme Viriato (2004, p. 47-48), que “[...] a política educacional implementada a partir da década de 1990 caracteriza-se, portanto, por ressignificar o papel do Estado como responsável pela condução financeira daquela [...]”. Entretanto, isso não significou que o Estado estrito, "mínimo para o social" e "máximo para capital", se tenha tornado fraco, pois

[...] o Estado náo perde o controle da política educacional; pelo contrário, planeja e indica diretrizes, responsabiliza os municípios e coopta 'cidadãos 
participantes' para uma prática fiscalizadora. Sendo assim, a participação aqui é canalizada para além da participação instrumental. É uma participação fiscalizadora, visto que é autossustentadora. Os 'cidadãos participantes' não criam, discutem, debatem objetivos e planejamento político educacional; eles praticam cobranças e executam aquilo que os órgãos centrais planejam. (VIRIATO, 2004, p. 48)

Rodriguez e Vieira (2012, p. 71), ao discutirem sobre a formação continuada de professores na Região Metropolitana de Campinas, afirmam que, no impasse descentralização/centralização, o que se verifica, efetivamente, a partir de 1994, é “[...] um processo de 'recentralização' e fortalecimento do nível federal sobre os outros, com a recomposição dos recursos fiscais e financeiros da Uniâo [...]".

\section{FORMAÇÃO CONTINUADA NO BRASIL}

Ao analisar a Tabela 1, podemos afirmar algumas características centrais da formação dos professores no Brasil:

a) $\mathrm{Na}$ federação o âmbito municipal é o que requer maior atenção, principalmente na educação infantil e no ensino fundamental, suas principais responsabilidades federativas. A formação docente não alcança, em nenhum nível, $75 \%$ de cobertura; e o ensino infantil, de grande expansão na última década, apenas cobre $65 \%$ dos docentes.

b) Maior preocupação apresenta o setor privado, em que, no ensino infantil menos de $50 \%$ dos professores possuem a formação exigida por lei.

c) A situação é melhor nos anos finais do ensino fundamental em que a cobertura se aproxima dos $90 \%$. 


\section{Tabela 1}

Percentual de docentes com curso superior por etapa de ensino - Brasil 2013

\begin{tabular}{|c|c|c|c|c|c|c|c|}
\hline & \multicolumn{3}{|c|}{ Ensino Infantil } & \multicolumn{3}{|c|}{ Ensino Fundamental } & \multirow[b]{2}{*}{ Ensino Médio } \\
\hline & Total & Creche & Pré-escola & Total & $\begin{array}{c}\text { Anos } \\
\text { Iniciais }\end{array}$ & $\begin{array}{l}\text { Anos } \\
\text { Finais } \\
\end{array}$ & \\
\hline Total & 60.8 & 59.6 & 62.3 & 79 & 72.2 & 84.6 & 93.1 \\
\hline Federal & 81.8 & 79 & 85.7 & 97.9 & 94,5 & 99.3 & 98.3 \\
\hline Estadual & 75.3 & 76.4 & 74.8 & 90.7 & 83.6 & 92.7 & 93.3 \\
\hline Municipal & 66.8 & 66.4 & 67.5 & 74 & 72.6 & 76 & 85 \\
\hline Privada & 47.5 & 48 & 49 & 73.9 & 63.3 & 85.9 & 91.9 \\
\hline Público & 66.9 & 66.4 & 67.6 & 80.1 & 74.6 & 84.3 & 93.5 \\
\hline
\end{tabular}

Fonte: MEC-INEP (2013).

Interessa destacar, aqui, a importância das políticas de formação de professores para enfrentar um dos principais problemas da educação no Brasil. Como já referido anteriormente, todos os diagnósticos são coincidentes neste quesito para recuperar a qualidade da educação.

\section{A FORMAÇÃO DE PROFESSORES NO BRASIL NOS PRIMÓRDIOS DO SÉCULO XXI}

A Política Nacional de Formação de Professores pode ser tratada em dois níveis diferentes: a Formaçáo Inicial do professor e a Formação Continuada em Serviço, que envolve mais de dois milhóes de professores no sistema educativo nacional.

O processo de descentralização da educação no Brasil - consolidado pelo sistema de financiamento, a partir de 1997, com a aprovação do Fundo de Manutenção e Desenvolvimento da Educação Fundamental (Fundef), e aprofundado com Emenda Constitucional no 53, de 19 de dezembro de 2006, a qual deu origem ao Fundo de Manutenção e Desenvolvimento da Educação Básica e de Valorização dos Profissionais da Educação (Fundeb), que passou a incorporar todos os níveis educativos que compóem o Ensino Básico do sistema - colocava uma interrogação 
sobre as capacidades de os sistemas municipais responderem adequadamente às novas responsabilidades que a municipalização estabelecia para as frágeis estruturas institucionais existentes nos municípios brasileiros. Os documentos oficiais convocavam a colaboraçẫo federativa para minorar as incertezas. No entanto, são constatáveis as enormes dificuldades para implantar na prática a política de colaboração e articulação dos entes na Federação.

A partir de 2006, a política de formação de professores existente, desarticulada e fragilizada na década de 1990, sofreu um reposicionamento da esfera federal, consolidando uma tendência à recentralização/concentração nas políticas públicas federais de formação de professores ${ }^{2}$. O processo em destaque realiza uma recentralização na União e uma concentração da política nacional de formação no Ministério da Educaçẫo (MEC).

Nos anos recentes, o governo federal, detectando a grande dispersão e a fragmentação das políticas docentes no país, bem como os descompassos entre os programas de formação para o magistério a cargo das Instituiçóes de Ensino Superior (IES) e o seu pífio resultado diante das demandas da Educação Básica, tomou uma série de iniciativas político-institucionais, com vista a sua promoçẫo e articulação. Particularmente no âmbito das instituiçóes públicas, procurando assegurar, no discurso oficial, uma educação de qualidade como direito de todos.

A configuração do grande aparato institucional montado pelo MEC, ao longo de pouco mais de meia década, delineia uma política nacional de formação docente orientada pela perspectiva de institucionalização de um sistema nacional de formaçáo que acompanhe o avanço do processo de responsabilizaçáo do poder público pelo desempenho, pela carreira dos professores da educação básica e pela sua formação.

Assim, o novo aparato, visa também fazer face à demanda pela Formação Inicial em nível superior exigida pela Lei no 9.394/1996, (BRASIL, 1996); e expande-se pela Formação Continuada em Serviço. Demanda essa que implica o atendimento de milhóes de docentes, assim como a diversificação da oferta segundo as etapas e as modalidades da educação básica, as características dos alunos e as necessidades regionais e locais. 
A primeira medida data de junho de 2006, quando o governo federal criou o Sistema Universidade Aberta do Brasil (UAB), Decreto ${ }^{\circ}$ 5.800/06, que propóe articular um sistema nacional de educação a distância, contando, para isso, com participação da Secretaria de Educação a Distância do MEC e do já existente Consórcio Universidade Virtual Pública Brasileira (Unirede). Reformulou-se a Diretoria de Educação a Distância, ligada à Coordenadoria de Aperfeiçoamento de Pessoal de Nível Superior (Capes), com a incorporação da Secretaria de Educação a Distância do MEC, com o objetivo de oferecer Formação Inicial e Continuada de professores, utilizando metodologias de educação a distância ${ }^{3}$. Para isso, integrou a EAD na formação inicial do professor, modalidade de ensino sempre recusada pelos órgãos profissionais do sistema e procurada pelo setor privado. A partir dessa mudança, pelo Decreto no 5.622 de 2005, o crescimento da educação a distância tornou-se explosivo na formação inicial de professores, com ampla predominância do setor mercantil.

Entre 2002 e 2013 operou-se uma inversão nas matrículas entre o setor público e o privado: em 2002, 14\% das matrículas em EAD encontravam-se nas instituiçôes privadas e $84 \%$ nas públicas; em 2012, de 449.966 matrículas na educação a distância nas licenciaturas, das quais $341.146(75,45 \%)$ em instituiçóes privadas e 108.820 (24,18\%) em instituiçôes públicas. (BERBAT, 2015) Vale lembrar a forte indução dos organismos internacionais, em particular o Banco Mundial, no processo de orientação dessas políticas. (SILVA, 2002)

No entanto, o grande reposicionamento da União na política de formação de professores foi realizado em 2007, quando a Lei $\mathrm{n}^{\circ}$ 11.502/07 reformulou estrutura e competências da Capes, e a instituição passou a ter a responsabilidade por coordenar as estruturas do Sistema Nacional de Formação de Professores da educação brasileira de ensino básico.

Destarte, a forte recentralização/concentração federativa se concretizou no Plano Nacional de Formação de Professores da Educação Básica (Parfor/2007). A formulaçáo do Parfor compreende um conjunto de açóes do MEC (políticas e financeiras), em colaboração com as secretarias de Educação de estados, municípios e com as IES participantes, 
para ministrar cursos superiores a professores em exercício em escolas públicas que não possuam a formação adequada explicitada na LDB/96.

O Parfor integra o Plano de Ações Articuladas (PAR), no bojo do Plano de Desenvolvimento da Educação (PDE), ao qual aderiram todos os entes federados. A Capes gerencia, acompanha e avalia o processo de proposição, inscrição e execução dos planos estratégicos dos estados em parceria com as IES. Esta política está fundamentada, conforme disposto no Decreto no 6.755/09, que instituiu a Política Nacional de Formação de Profissionais do Magistério da Educação Básica e disciplinou a atuação da Capes no fomento a programas de formação inicial e continuada, além de outras providências. Podemos citá-la como exemplo de recentralização/concentração do processo em curso.

Complementarmente, a Capes criou um sistema informatizado, a Plataforma Freire, pelo qual os professores das redes públicas se candidatam, integrando um forte impulso à nova política de formação nacional de professores, com apoio de tecnologias e a distância.

\section{FORMAÇÃO EM CONTEXTOS DESCENTRALIZADOS}

Durante esse período, municípios brasileiros desenvolveram experiências próprias, diversas, de formação de professores, que são pouco conhecidas ou sistematizadas. E quase nunca consideradas nas políticas centralizadas na União, pois na política nacional de formação não existe um trabalho de sistematização das experiências municipais do período.

Diversas pesquisas tentam discutir tais experiências ${ }^{4}$. Algumas das discussóes mais presentes podem ser assim apresentadas:

- A necessidade de criar instituiçóes mais profissionalizadas e permanentes ou não: Hortolândia e Campinas definiram pela criação de Centro de Formação de Professores 5 . Diferentemente, a experiência de Paulínia foi realizar a formação de professores no processo de construçáo do currículo sem estrutura institucional permanente. Como é de imaginar, questóes como a forma de incorporar conhe- 
cimento e inovaçóes, bem como o planejamento na formação de professores tomaram relevância nesses municípios.

- A questão da participação também apareceu recorrentemente: as formas de convocação e a participação docente; a elaboração dos programas e das atividades de formação com envolvimento dos professores ou decorrentes de decisóes centralizadas em gabinetes tornaram-se uma constante nas pesquisas.

- A responsabilidade pública e privada neste processo se apresentou diversas vezes, particularmente em relação à privatização através empresas de consultoria educativa.

- Variadas propostas surgiram para realização das atividades de Formação dos Professores nas diferentes redes de ensino. Interessa destacar aqui a diferença entre municípios maiores e menores e a existência de municípios de maior renda e, principalmente, de herança institucional e conhecimento acumulado entre as diferentes redes como fatores de grande impacto para os resultados das pesquisas.

- A relação federativa entre as diferentes dependências administrativas. Neste caso particular, ressaltou-se a evidente dificuldade de operacionalizar a colaboração federativa convocada pela legislação e pelos Planos Nacionais da Educação.

Esta discussão poderia alongar-se; no entanto, nosso objetivo é destacar o processo de recentralização em curso e suas ligaçóes com a reforma do Estado capitalista brasileiro frente à crise global. E assinalar, apenas, a forte desconsideração das experiências municipais de formação de professores existentes.

\section{A MODERNIZAÇÃO GERENCIAL DAS POLÍTICAS ESTATAIS}

Conforme discussão realizada, podemos asseverar que o processo de redefinição da relaçáo Estado/sociedade, que se assenta na perspectiva do Estado capitalista, ora hegemônico, tem, com base no processo de recentralização/concentração das políticas públicas de formação de professores, servido como estratégia privilegiada de tentativa de estabelecer o consenso em torno da utilização de mecanismos geren- 
ciais oriundos do campo empresarial, como o planejamento estratégico e a avaliação por resultados.

Assim, importa destacar que tal orientação tem sido implementada a partir da orientação do programa político da "terceira via", que fundamentou o processo de reforma do Estado na última década do século XX e que vem servindo de fundamentação para a política educacional neste início de século XXI.

Com o objetivo de retomar o crescimento econômico na primeira década do presente século, foi instituído em 22 de janeiro de 2007, no segundo mandado do presidente Luiz Inácio Lula da Silva, o Programa de Aceleraçáo do Crescimento (PAC), que, segundo dados oficiais, incorporou inovaçóes na gestáo dos recursos orçamentários dos projetos estratégicos e ampliou as funçôes de coordenação da ação governamental, com a adoção da gestão gerencial.

Como desdobramento do PAC, foi lançado o Plano de Desenvolvimento da Educação (PDE). Caracterizado como um plano executivo, propala a melhoria da qualidade da educação, mediante um conjunto de medidas. (BRASIL, 2007a)

Como elemento estruturador do PDE, foi lançado em 24 de abril de 2007 o Decreto no 6.094, que instituiu o Plano de Metas Compromisso Todos pela Educação que buscou orientar o estabelecimento de políticas em regime de colaboração entre municípios, Distrito Federal e estados, com participação ativa das famílias e da comunidade. (BRASIL, 2007b)

Como elemento aferidor da qualidade da educação básica, instituiu-se, pelo mesmo decreto, em seu capítulo II, art. $3^{\circ}$, o Índice de Desenvolvimento da Educação Básica (Ideb), calculado e divulgado periodicamente pelo Instituto Nacional de Estudos e Pesquisas Educacionais Anísio Teixeira (Inep), com base em dados sobre rendimento escolar, combinados com o desempenho dos alunos, constantes do censo escolar e do Sistema de Avaliação da Educação Básica (Saeb), composto pela Avaliação Nacional da Educação Básica (Aneb) e pela Avaliação Nacional do Rendimento Escolar (Prova Brasil). 
Outro elemento constitutivo da atual política educacional é o Plano de Açóes Articuladas (PAR) - referendado no Decreto 6.094, capítulo IV, seção II, art. $9^{\circ}-$, que estabelece as bases para termo de convênio ou de cooperação, de caráter plurianual, firmado entre o Ministério da Educação e o ente apoiado.

De modo geral, o PAR pode ser caracterizado como um conjunto articulado de açóes, apoiadas técnica e/ou financeiramente pelo MEC, que visam ao cumprimento e à observância das diretrizes e metas do Compromisso Todos pela Educação.

Conforme a presente análise, um aspecto central que perpassa essa orientação é a institucionalização da mobilização social como instrumento refuncionalizado de legitimação de uma proposta política de gestâo gerencial, supostamente atrelada à melhoria da qualidade da educação básica.

Com isso, nota-se uma tendência crescente de transposição de mecanismos provenientes da área privada, como plano estratégico e avaliação por resultados, que chegam à escola sob o véu da participação e da gestão democrática. É mister destacar que tal tendência passou a ser reiterada no atual Plano Nacional de Educação.

Com efeito, foi sancionada pela Presidente Dilma Rousseff a Lei no 13.005, de 25 de junho de 2014, que "Aprova o Plano Nacional de Educação - PNE e dá outras providências". (BRASIL, 2014)

O PNE em vigor é composto por 20 metas e 254 estratégias, e apresenta em seu art. $2^{\circ}$ o enunciado das seguintes diretrizes:

(I) erradicação do analfabetismo; (II) universalização do atendimento escolar; (III) superação das desigualdades educacionais, com ênfase na promoção da cidadania e na erradicação de todas as formas de discriminação; (IV) melhoria da qualidade da educação; (V) formação para o trabalho e para a cidadania, com ênfase nos valores morais e éticos em que se fundamenta a sociedade; (VI) promoçáo do princípio da gestâo democrática da educação pública; (VII) promoção humanística, científica, cultural e tecnológica do País; (VIII) estabelecimento de meta de aplicação 
de recursos públicos em educação como proporção do Produto Interno Bruto - PIB, que assegure atendimento às necessidades de expansão, com padrão de qualidade e equidade; (IX) valorização dos (as) profissionais da educação; $(\mathrm{X})$ promoção dos princípios do respeito aos direitos humanos, à diversidade e à sustentabilidade socioambiental.

Conforme consta no plano, a meta 15 versa a respeito da política nacional de formação dos profissionais da educação. O documento propóe que, no prazo de um ano de sua vigência, seja instituída em regime de colaboração:

[ a ] política nacional de formaçấo dos profissionais da educação de que tratam os incisos I, II e III do caput do art. 61 da Lei no 9.394, de 20 de dezembro de 1996, assegurado que todos os professores e as professoras da educação básica possuam formação específica de nível superior, obtida em curso de licenciatura na área de conhecimento em que atuam. (BRASIL, 2014)

Com esse intuito, propóe-se, por meio da meta 16, formar, em nível de pós-graduação:

[...] 50\% (cinquenta por cento) dos professores da educação básica, até o último ano de vigência deste PNE, e garantir a todos (as) os (as) profissionais da educação básica formação continuada em sua área de atuação, considerando as necessidades, demandas e contextualizaçóes dos sistemas de ensino. (BRASIL, 2014)

Para a realização dessa meta, dentre as propostas, encontram-se as seguintes estratégias: realizar, em regime de colaboração, o planejamento estratégico para dimensionamento da demanda por formação continuada e fomentar a respectiva oferta por parte das instituiçóes públicas de edu- 
cação superior, de forma orgânica e articulada às políticas de formação dos estados, do Distrito Federal e dos municípios; ampliar a oferta de bolsas de estudo para pós-graduação dos professores e demais profissionais da educação básica.

\section{A HEGEMONIA DO CAPITAL FINANCEIRO}

O Estado capitalista materializa a hegemonia da classe dominante no seu interior. $\mathrm{O}$ grande capital financeiro internacional organiza o processo de acumulação de capital. No caso do setor educativo brasileiro, a acumulação de capital conduz um expressivo processo de centralização, internacionalização e financeirização do capital educacional. E as políticas públicas apontam para realização de compromissos de classe, sinalizando com a expansão da oferta e a universalização da cobertura. A expansão do ensino superior brasileiro por meio da privatização nas empresas educacionais e o financiamento público da expansão privada, sob uma condução financeira, tornam-se exemplos históricos do modelo teórico-analítico desenvolvido na primeira parte do texto.

As análises sobre o modelo de acumulação de capital sob a forma "financeirizada" do capital destacam a agudização dos traços fraudulentos, predatórios e violentos da acumulação atual. Harvey (2013) utiliza o conceito de acumulação por espoliação para identificar a especificidade deste momento.

\section{A ARTICULAÇÃO DE SISTEMAS EDUCATIVOS E A COLABORAÇÃO FEDERATIVA}

As políticas públicas educacionais impulsionadas pelo "novo gerencialismo", de forte tendência centralizadora, propóem a colaboração dos diferentes entes federativos como condiçáo de sucesso das propostas. Esse discurso lacunar, ideológico, esconde as reais dificuldades existentes na federação brasileira e no âmbito educativo para funcionar no sistema de colaboração, em razão da lógica gerencial e da presença de rivalidades 
políticas entre o executivo e o legislativo, nas diferentes dependências da federação.

Segundo Cury (2010, p. 149), "[...] o tratamento e a avaliação das políticas educacionais, no Brasil, exigem, entre outros critérios e cuidados, o de considerar a opção de sermos uma República Federativa [...]". Nesse sentido, Saviani (2014, p. 29) explica que, “[...] sendo a federação a unidade de vários estados que, preservando suas respectivas identidades, intencionalmente se articulam tendo em vista assegurar interesses e necessidades comuns, a federação postula o sistema nacional $[\ldots] "$.

Tais argumentos permitem-nos ratificar nossa observação a respeito do caráter ideológico do conceito de colaboraçáo federativa, no contexto do gerencialismo, pautado pela fragmentação entre o estratégico e o operacional, no qual se assentam as propostas centralizadoras das políticas educacionais.

\section{À GUISA DE CONCLUSÃO}

Este artigo procura estabelecer, na discussão atual, a importância de as análises serem conduzidas em duas direçóes:

a) A incorporação de uma compreensão do Estado capitalista que retoma a ideia de Poulantzas (2000), segundo o qual este se constitui como uma condensação das relaçóes de forças entre classes e fraçóes de classe, expressando as contradiçôes do modo de produção. Nesse sentido, o Estado é fundamental para a realização do capital e para a orientaçấo das políticas públicas, tais como a formação de professores.

b) A identificação, nas políticas públicas concretas, dos aspectos que fundamentam a análise teórica assumida. Para tanto, destacamos o problema da concentração, num ente da Federação, da política de formulação e do processo decisório sobre a política nacional de formação de professores adotada no Brasil. Por fim, importou-nos alertar para as implicaçóes da realização da proposta gerencialista, com o seu pseudointuito de melhorar o desempenho educacional e a recuperação da qualidade de ensino. 
Em suma, estas notas estão alinhadas com base em observaçôes que apontam limites às proposições que vêm assumindo as políticas gerenciais governamentais e que também póem em relieve os efeitos privatizantes para a educação e problemáticos para federação brasileira.

\section{REFERÊNCIAS}

ANDERSON, P. Renovação. Revista Praga-Estudos Marxistas, São Paulo, n. 9, p. 7-26, jun. 2000.

BERBAT, M. da C. Pró-licenciatura e a experiência de formaçáo de professores para a Educaçáo Básica. 2015. 290 f. Tese (Doutorado em Educação) - Faculdade de Educação, Universidade Estadual de Campinas, Campinas, SP., 2015.

BRASIL. Lei no 13. 005, de 25 de junho de 2014. Aprova o Plano Nacional de Educação - PNE - e dá outras providências. Brasília, DF., Diário Oficial da Uniáo, 26 jun. 2014. Disponível em: <http://www.planalto.gov.br/ccivil 03/ Ato2011-2014/2014/Lei/L13005.htm>. Acesso em: 28 jun. 2014.

. Ministério da Administração e Reforma do Estado. Plano diretor da reforma do aparelho de Estado. Brasília, DF.: MARE, 1995.

. Ministério da Educação e do Desporto. Lei no 9. 394, de 20 de dezembro de 1996. Estabelece as diretrizes e bases da educação nacional. Brasília, DF., Diário Oficial da Uniáo, 23 dez. 1996. Disponível em: $<$ http://www.planalto. gov.br/ccivil 03/leis/19394.htm>. Acesso em: 08 dez. 2014.

. Ministério da Educaçáo. Decreto Presidencial n. 6.094, de 24 de abril de 2007. Dispóe sobre a implementação do Plano de Metas Compromisso Todos pela Educação, pela União Federal, em regime de colaboração com Municípios, Distrito Federal e Estados, e a participação das famílias e da comunidade, mediante programas e açốes de assistência técnica e financeira, visando a mobilização social pela melhoria da qualidade da educação básica. Brasília, DF., Diário Oficial da Uniáo, 24 abr. 2007a.

- Ministério da Educação. O Plano de Desenvolvimento da Educação: razões, princípios e programas. Brasília, DF.: MEC, 2007 b.

CASASSUS, J. Tarefas da educação. Campinas: Autores Associados, 1995. 
CURY, C. R. J. A questão federativa e a educação escolar. In: OLIVEIRA, R. P. de; SANTANA, W. (Org.). Educaçâo e federalismo no Brasil: combater as desigualdades, garantir a diversidade. Brasília: UNESCO, 2010.

GIDDENS, A. A terceira via e seus críticos. Rio de Janeiro: Record, 2001.

. A terceira via: reflexóes sobre o impasse político atual e o futuro da social-democracia. 5. ed. Rio de Janeiro: Record, 2005.

- Para além da esquerda e da direita. O futuro da politica radical. São Paulo: Editora da Unesp, 1996.

GRAMSCI, A. Cadernos do cárcere. Os intelectuais. O princípio educativo. Jornalismo. v. 2, 5. ed. Rio de Janeiro: Civilização Brasileira, 2010.

HARVEY, D. O novo imperialismo. 7. ed. São Paulo: Loyola, 2013.

MARTINS, M. F.; GROPPO, L. A. Sociedade civil e educação: fundamentos e tramas. Campinas: Autores Associados, 2010.

MONTAÑO, C. Terceiro setor e questão social: crítica ao padrão emergente de intervenção social. 4. ed. São Paulo: Cortez, 2007.

POULANTZAS, N. O Estado, o poder, o socialismo. 2. ed. Rio de Janeiro: Graal, 2000 .

RODRIGUEZ, V; VIEIRA, M. Descentralização e formação continuada de professores na RMC. Pro-Posiçóes, Campinas, SP, v. 23, n. 2, p. 67-90. 2012. Disponível em: <http://ref.scielo.org/jhb79y>. Acesso em: 12 mar. 2015.

SAVIANI, D. Sistema Nacional de Educação e Plano Nacional de Educação: significado, controvérsias e perspectivas. Campinas, SP: Autores Associados, 2014.

SILVA, D. P. da; RODRIGUEZ, V. A política educacional brasileira no contexto do gerencialismo contemporâneo. In: SEMINÁRIO SOBRE “A PRODUÇÃO DO CONHECIMENTO EM EDUCAÇÃO”, 2013, São Paulo. Anais... São Paulo: PUC/SP, 2013. p. 125-132.

SILVA, M. A. da. Intervenção e consentimento: a política educacional do Banco Mundial. São Paulo, Fapesp: Autores Associados, 2002.

VIRIATO, E. O. Descentralização e desconcentração como estratégia para redefiniçãao do espaço público. In: LIMA, A. B. de (Org.). Estado, politicas educacionais e gestão compartilhada. São Paulo: Xamã, 2004.

WOOD, E. M. Democracia contra o capitalismo: a renovação do materialismo histórico. São Paulo: Boitempo, 2006. 


\section{NOTAS}

1. "Organizaçôes sociais são entidades de direito privado, sem fins lucrativos, que tenham autorização específica do poder legislativo para celebrar contrato de gestão com o poder executivo e assim ter direito a dotaçấo orçamentária” (BRASIL, 1995, p. 46-47).

2. Tendência que se soma à já existente na esfera fiscal; lembre-se dos anos 1990. A União, por meio de taxas e contribuições (impostos indiretos), escapa da regulamentação constitucional, que determina uma forte descentralização dos impostos, diminuindo, assim, a participação dos recursos totais da uniâo nos recursos vinculados constitucionalmente pelo regime fiscal brasileiro. $\mathrm{O}$ crescimento de recursos indiretos, de distribuição discricionária, desfigura o "espírito" da descentralização fiscal da federação brasileira pós1989.

3. A UAB possuía, em 2014, 736 cursos e 277 mil matrículas em 91 Instituições Públicas de Ensino Superior.

4. Ver RODRIGUEZ, V. et al. Formação de Professores em contextos descentralizado: Região Metropolitana de Campinas-RMC. Relatório de Pesquisa, FE/Unicamp, 2014.

5. Centro de Formação Milton Santos, em Campinas, e Centro Paulo Freire, em Hortolândia.

Recebido em 01 de junho de 2015.

Aprovado em 15 de setembro de 2015.

DOI: http://dx.doi.org/10.1590/CC0101-32622015150379 